REJ - Revista de Estudios de la Justicia - No 3 - Año 2003

\title{
ESTATUS DE LA VICTIMA EN EL PROCESO PENAL COMENTARIO A DOS FALLOS DE LA CORTE SUPREMA
}

Maria Inés Horvitz Lennon *

\begin{abstract}
I. Breve relación de las sentencias y de los aspectos que resultan controvertidos; II. Comentario crítico al segundo fallo de la Corte Suprema; II.1. ¿Tiene el Ministerio Público un "derecho" al debido proceso?; II.2. ¿Cuál es la posición de la víctima en el nuevo proceso penal? ¿Puede tener el estatus de testigo?; II.3. ¿Tiene la víctima el mismo estatus que el imputado o son ellos equiparables?; II.4. ¿Puede la víctima ser compelida a declarar en el juicio?
\end{abstract}

\section{I.- Breve relación de las sentencias y de los aspectos que resultan controvertidos}

Con fecha 30 de Septiembre de 2002, la Corte Suprema resolvió un recurso de nulidad interpuesto por el Ministerio Público en contra de la sentencia definitiva de 24 de Junio del mismo año, pronunciada por el Tribunal de Juicio Oral en lo Penal de Temuco, que absolvió a los acusados de los cargos formulados por el delito de robo con intimidación ${ }^{1}$.

El Ministerio Público interpuso su recurso fundándose en las causales previstas en las letras a) y b) del artículo 373 del Código Procesal Penal (CPP), asegurando que en el juicio oral que dio lugar al fallo absolutorio se habrían infringido sustancialmente derechos o garantías asegurados por la Constitución y los tratados internacionales ratificados por Chile y actualmente vigentes, y porque en la dictación del fallo se hizo una errónea aplicación del derecho habiendo ello influido sustancialmente en lo dispositivo del mismo.

El recurrente señaló que la absolución recaída en el citado juicio se produjo como consecuencia de no haberse escuchado "la versión del testigo más importante de la Fiscalía como era la víctima", cuya comparecencia fue ordenada mediante arresto pero que, sin embargo, no compareció por no haber sido habido, ni aun al término del juicio; circunstancia que finalmente dio lugar a una solicitud, por parte del fiscal adjunto, de suspensión del juicio, petición que fue denegada por el tribunal colegiado.

Asimismo, el recurrente alegó, en lo que para este comentario resulta pertinente, que el tribunal se encontraba "en el deber de generar y garantizar un escenario de igualdad en el ejercicio de los derechos que a las partes les asisten" y que al negar la suspensión solicitada dio un tratamiento desmedrado al Ministerio Público, institución que carece de imperio para obligar a comparecer a la víctima, infringiéndose el principio de igualdad de armas, situación que influyó sustancialmente en la absolución de los imputados.

Respecto del principio de debido proceso alegado como infringido por el Ministerio Público, el máximo Tribunal expresa que "el carácter tutelar del proceso no

\footnotetext{
* Profesora Derecho Penal, Facultad de Derecho, Universidad de Chile.

1 Causa Rol Unico 0100037887-5, RIT No 018-2002, e Ingreso Corte Nº 2538-2002.
} 
Horvitz - Estatus de la víctima en el proceso penal

sólo asegura a la persona a quien se le desconoce un derecho que le sea reconocido, sino que, además, y para lo que nos interesa, si el Estado o un particular pretenden que se ejerza la potestad punitiva cuando se le imputa la comisión de un delito, asegura que la pena sea impuesta al imputado a través de un proceso que reúna las mínimas condiciones que autoricen al Estado para castigar" (considerando sexto).

Sin embargo, rechaza el recurso de nulidad interpuesto argumentando que "no puede aceptar las aseveraciones del recurrente en el sentido de que al negarse el tribunal a suspender la audiencia lo ha dejado en una situación de desmedro y de desigualdad (...)", pues el Código contempla reglas para evitar problemas como los producidos. A favor de su tesis, la Corte invoca las normas de los artículos 78 y 308 del CPP que imponen al Ministerio Público el deber de adoptar o solicitar las medidas de protección a la víctima que fueren procedentes, discurriendo en su razonamiento sobre la base de afirmar la calidad de testigo que la víctima puede asumir en el juicio. Incluso hace alusión a la posibilidad de haberse solicitado la declaración anticipada de la víctima ante el juez de garantía, en conformidad a los artículos 192 y 280 del CPP (considerando octavo).

La Corte argumenta, por otro lado, que la facultad de suspender la audiencia principal es una facultad y no una obligación del tribunal del juicio, la que debe adoptarse sobre la base de la ponderación del fundamento de "necesidad racional" a que se refiere el Código en su artículo 283. Añade que el tribunal del juicio rechazó la solicitud en tal sentido indicando que "se ve que no resulta posible encontrar al testigo aludido", evitando con ello infringir innecesariamente el principio de continuidad del juicio. El alto Tribunal concluye señalando que "negarle la suspensión al Ministerio Público no ha sido erróneo ya que en consideración a lo que se ha señalado antes de iniciar la acción penal tuvo que preocuparse de poder acompañar ante el tribunal del juicio oral y en la audiencia todos los antecedentes probatorios que pudieran comprobar la existencia de los hechos que suponía delictuosos y aquellos que comprobaran la participación culpable de los imputados" (considerando noveno).

Con fecha 2 de Octubre de 20022, esto es, sólo dos días después de haberse dictado el fallo anterior, la Segunda Sala de la Corte Suprema pronuncia un fallo que se opone radicalmente a una cuestión que parecía incontrovertida y evidente en el primero, esto es, la atingente al posible estatus de testigo de la víctima en el proceso penal y, más especialmente, en el juicio oral. En efecto, en la especie se trata nuevamente de un recurso de nulidad interpuesto por el Ministerio Público alegando las causales de las letras a) y b) del artículo $373 \mathrm{CPP}$ por, entre otras razones, haberse rechazado la solicitud de suspender la audiencia del juicio oral para posibilitar la concurrencia a declarar de la víctima quien no compareció no obstante las reiteradas citaciones efectuadas a su respecto. Se solicitó, incluso, su arresto "para vencer su injustificada resistencia a prestar testimonio en el proceso".

En cuanto a la causal invocada contenida en el letra a) del artículo 373 CPP, la Corte controvierte la posible extensión de la garantía del debido proceso al Ministerio Público, aunque sin pronunciarse en forma concluyente al respecto. Sobre el verdadero contenido del principio de igualdad de armas entre las partes, la Corte afirma que "el debido proceso (...) no tiene realmente por objeto instaurar el fair play entre contendientes de poderío equiparable, sino asegurar el respeto del más débil por parte de la potestad

2 Rol Unico 0100015692, RIT 013/2002, e Ingreso Corte No 1989-2002 
punitiva centralizada (...)". Más adelante añade que "por supuesto, y quizás por lo que venimos argumentando, no puede excluirse por completo la posibilidad de que también el Ministerio Público esté en situación de invocar la garantía del debido proceso pero, a la luz de cuanto se ha expresado, cabe afirmar que ello sólo ocurrirá en casos excepcionalísimos (...)" (considerando segundo).

En el considerando tercero, la sentencia se aboca derechamente a la cuestión reclamada y afirma categóricamente que la víctima “(...) a diferencia de lo que parece sostener el recurrente, no es un testigo, es decir, un tercero ajeno a dicho procedimiento pero que depone sobre hechos que interesa acreditar a los intervinientes en él, sino uno de estos últimos, como lo pone de manifiesto expresamente el Código Procesal penal en su artículo 12, que lo parangona con el fiscal, el imputado, el defensor y el querellante, al paso que el Título IV del Libro I de ese mismo cuerpo de leyes lo incluye, en su párrafo $6^{\circ}$, entre los sujetos procesales (...)"3. En base a las normas citadas, la Corte expresa que "no puede deducirse que gravite sobre el ofendido una especie de obligación de hacerse oír a toda costa cuando el Ministerio Público o el tribunal lo juzgue oportuno para el éxito de la investigación o para el esclarecimiento de los hechos". Añade que "esta obligación existe para el testigo (...)"; sin embargo, la víctima, en cuanto sujeto procesal, podría "declinar su interés en los resultados de éste $y$, por consiguiente, su derecho a expresar su verdad sobre los hechos"4. Finalmente, y haciendo un paralelo con la situación procesal del imputado, la Corte advierte sobre lo paradójico que podría resultar que mientras este último puede guardar silencio o decir lo que considere conveniente, "el ofendido, en cambio, se viese forzado a prestar declaración, incluso contra su voluntad. $\mathrm{Y}$, sin embargo, a esto último - concluye el máximo tribunal- tiende la pretensión de apercibirlo con un arresto si no accede a concurrir al juicio oral y a declarar en él”. Rechaza, pues la "victimización secundaria" que esta posibilidad ocasionaría en la víctima ${ }^{5}$ y aboga porque el Ministerio Público obtenga la cooperación de la víctima en forma voluntaria; de lo contrario, "no le resta más que resignarse a prescindir de ella" . En base a estas y otras consideraciones, la Corte rechaza el recurso de nulidad interpuesto por el Ministerio Público.

\section{II.- Comentario crítico al segundo fallo de la Corte Suprema}

En primer lugar, no cabe sino mostrar sorpresa respecto del cambio sustancial en la posición del alto Tribunal con relación al estatus de testigo que puede asumir la víctima en el nuevo proceso penal, hecho que resulta comprobable con la sola lectura de los fallos individualizados, que fueran dictados sólo con dos días de diferencia por la misma Sala de la Corte Suprema.

En efecto, no cabe duda que el primer fallo discurre sobre la base de presumir la calidad de testigo de la víctima que es citada a declarar al juicio oral; la problemática que la Corte plantea en esta sentencia gira mas bien sobre la posibilidad de reconocerle al Ministerio Público un supuesto derecho a la suspensión del juicio como forma de cautelar la igualdad de armas en el juicio. En cambio, la segunda sentencia niega explícitamente la

\footnotetext{
${ }^{3} \mathrm{El}$ destacado es nuestro.

${ }^{4}$ El destacado es nuestro.

${ }^{5}$ Considerando $5^{\circ}$ de la sentencia comentada.

${ }^{6}$ Considerando $5^{\circ}$ in fine, de la sentencia comentada.
} 
Horvitz - Estatus de la víctima en el proceso penal

calidad de testigo de la víctima en el proceso penal y, en consecuencia, plantea dudas respecto a las aseveraciones del primer fallo que dan por supuesta o asumen dicha calidad en la víctima?.

Para abordar de modo sistemático nuestro comentario, dividiremos el análisis en los siguientes temas que plantearemos como interrogantes:

1.- ¿'Tiene el Ministerio Público un "derecho" al debido proceso?

2.- ¿Cuál es la posición de la víctima en el nuevo proceso penal? ¿Puede tener el estatus de testigo?

3.- ¿Tiene la víctima el mismo estatus que el imputado o son ellos equiparables?

4.- Y finalmente, ¿puede la víctima ser compelida a declarar en el juicio?

\section{II.1. ¿Tiene el Ministerio Público un “derecho” al debido proceso?}

La segunda sentencia de la Corte Suprema orienta una buena parte de su razonamiento a rechazar la posibilidad de que el Ministerio Público invoque la garantía del debido proceso a su favor, aunque la admite excepcionalmente ${ }^{8}$.

Para aclarar este punto, hay que recordar, siquiera brevemente, el origen histórico de esta garantía. No cabe duda de que ella aparece indisolublemente ligada a la idea de poder punitivo del Estado. En la primera forma social, el poder penal se ejerce por la víctima y su tribu; un modelo clásico es el derecho germano antiguo al que se atribuye un tipo acusatorio privado de enjuiciamiento criminal $^{9}$. A partir del siglo XIII, con el surgimiento de los estados nacionales, se produce la centralización paulatina del poder político y con ello, del poder punitivo. Esta transferencia del poder penal, de manos del individuo al Estado, si bien representó un paso adelante en el modo de resolver más civilizadamente los conflictos más graves desde el punto de vista social, al evitar la venganza privada, significó al mismo tiempo la entrega al Estado del medio más poderoso de control social. Los excesos y abusos cometidos a través de este instrumento en la época del absolutismo provocaron la necesidad de poner límites al mismo, de someterlo a la razón; de este esfuerzo da cuenta, entre otras, la obra magna de Beccaria, Dei delitti e delle pene ${ }^{10}$. En suma, con la creación del Estado de Derecho, se declaran una serie de derechos y garantías que buscan proteger a los individuos, miembros de una comunidad determinada, contra el uso arbitrario e ilimitado del ius puniendi estatal. Tales derechos y garantías, cuyos titulares son los ciudadanos, dan origen a una serie de principios que suelen estar constitucionalizados; ellos se traducen en valores que en los diferentes ordenamientos jurídicos modernos, incluido el nuestro, aparecen como superiores en rango a la misma potestad penal del Estado ${ }^{11}$.

De lo dicho se desprende que no existe un "derecho" ni una "garantía" al debido proceso por parte del Ministerio Público, el órgano del Estado en la persecución penal

\footnotetext{
${ }^{7}$ Cfr. especialmente considerando octavo del fallo.

${ }^{8}$ Considerando segundo.

${ }^{9}$ Sobre el particular, y extensamente MAIER (J) Derecho procesal penal. I. Fundamentos, $2^{\mathrm{a}}$ reimpresión, Editores del Puerto, 1999 , pp. 259 y ss.

${ }^{10}$ De los delitos y de las penas, traducción de J.A. de las Casas, Ed. Alianza, Madrid, 1969.

11 Vid. MAIER, cit., pp. 471 y ss.; HORVITZ (M.I)/LOPEZ (J): Derecho procesal penal cbileno, Tomo I, Capitulo

II, Editorial Jurídica de Chile, Santiago, 2002, passim.
} 
pública de los delitos, porque las garantías surgen siempre en relación a un imputado, esto es, una persona a quien se le atribuye la comisión de un delito. Y por lo mismo, no compartimos el razonamiento del voto disidente de ambos fallos en comento, cuando señala que la garantía del debido proceso "debe respetarse respecto de todas las partes del juicio, y en este caso tanto del Ministerio Público, representante de la sociedad en la investigación en todo proceso penal, como a favor del o de los imputados"12. Todo el sistema de derechos y garantías en este ámbito se estructura a partir de la noción de "imputado" o de "individuo a quien se dirige una imputación penal", garantías que se hacen valer frente o, incluso, contra el Estado. De allí que parezca absurdo que el propio órgano estatal pueda esgrimirlas en su favor, pues lo que está en juego son los bienes de quien, hasta que no recaiga sentencia definitiva condenatoria en el juicio, debe ser presumido inocente. Respecto del Estado sólo está en juego la eficacia de su poder punitivo. Por otro lado, se parte del reconocimiento que, fácticamente, no existe igualdad de armas entre el Estado y el inculpado; por ello, y como señala la sentencia que comentamos, se trata mas bien de "asegurar el respeto del más débil por parte de la potestad punitiva centralizada"13.

En el sentido aquí enunciado se ha pronunciado expresamente MAIER, a propósito de cierta jurisprudencia argentina que este autor critica y rechaza ${ }^{14}$. No obstante su extensión, consideramos de suma relevancia transcribir íntegramente su opinión por tener directa relación con la doctrina del fallo que comentamos. Refiriéndose al derecho a defensa expresa que “(...) esta garantía es, como las demás, garantía frente al poder del Estado, y como ellas, representa, propiamente, una limitación del poder estatal. De allí que se equivoca quien extiende el funcionamiento de la garantía al órgano estatal en cuyas manos se coloca el poder de persecución penal. La ley procesal penal puede otorgar facultades al Ministerio Público, colocándolo en un pie de igualdad con el imputado, o, incluso como sucede en realidad, por encima de él, pues ejerce el poder de persecución penal del estado y goza de todas las facultades que ello implica (por ej., el de dirigir la policía); pero ello no significa regular su defensa y otorgarle oportunidades para ejercer ese derecho, sino, simplemente, darle armas para cumplir su función. Cuando, por error judicial, se le niega alguna de las atribuciones que posee (por ej., informar después de la recepción de la prueba en el debate) la sentencia se podrá anular, si él la recurre (casación), pero nunca bajo el fundamento de que se "violó la defensa" del Ministerio Público, sino bajo el más racional de que no se ha cumplido el procedimiento que la ley prevé para arribar a ella, omitiéndose un acto previsto (siempre una nulidad relativa, sujeta a ciertas condiciones, que no invalida por sí la decisión). Es por ello que el Ministerio Público vería impedida su concurrencia ante la Corte Suprema, como tribunal de casación constitucional, bajo la invocación de que a él no se le ha respetado la "garantía" de su defensa. Decidir otra cosa sería malinterpretar gravemente el sentido de las garantías individuales como limitadoras del poder del Estado, pretendiendo que el mismo Estado, en el ejercicio de su poder público, recibe amparo de estas cláusulas"15. Más adelante se refiere a una interpretación "errónea" o "más aún, sofística" efectuada por la Corte Suprema argentina ${ }^{16}$ por la que anula una absolución sobre la base de un

\footnotetext{
12 Considerando b) del voto disidente del Ministro Sr. José Luis Pérez Zañartu.

13 Considerando $2^{\circ}$, fallo 2.10 .02 .

14 Hace alusión expresamente al fallo de la Corte Suprema Nacional caratulado "Jofré, Hilda y otra, de 24 de Marzo de 1994, publicado en Doctrina Penal, periódico de 14 de Septiembre de 1994, al que aludiremos más adelante.

15 MAIER (J) Derecho procesal penal, cit., pp. 543-4.

16 Sentencia individualizada en nota anterior
} 
Horvitz - Estatus de la víctima en el proceso penal

recurso del Ministerio Público, que reclama por haberse conculcado en el procedimiento su derecho de defensa. Al efecto, MAIER señala que "en el caso, el tribunal arribó a la solución por exclusión de medios de prueba introducidos por el fiscal, que consideró ilegítimos para ser valorados en la sentencia, en virtud de estar alcanzados por prohibiciones probatorias específicas (...). La CSN consideró que la exclusión de estos elementos de la valoración del tribunal para la sentencia lesionaba la garantía constitucional del debido proceso... a favor del Estado y, por ello, casó la sentencia"17. A juicio del profesor argentino, "esta manera de argumentar y de interpretar las garantías individuales, en contra del individuo y a favor del Estado, persecutor penal, que se repite peligrosamente en nuestra jurisprudencia, incluida la de tribunales superiores, conduce a pensar que la única garantía consiste en eliminar el recurso del Ministerio Público, acusador estatal que, conforme a ello, sólo tendrá una oportunidad para perseguir y lograr la condena del acusado (ne bis in idem en sentido estricto), frente al tribunal del juicio."18

Por las razones invocadas, no puede existir un "derecho a la suspensión del juicio" por parte del Ministerio Público, ni en cuanto "derecho" ni, si existiera, en cuanto él pudiera recaer sobre la "suspensión del juicio". Porque la única garantía reconocida por el ordenamiento jurídico es la del imputado a la continuidad del juicio, a fin que el tribunal lo juzgue únicamente en base a las pruebas producidas durante el juicio ${ }^{19}$, al punto que su infracción constituye motivo absoluto de nulidad (art. 374 letra d) CPP). Dar vuelta la garantía y entenderla como un "derecho a suspender el juicio" es trastocar completamente el sentido y significación de la misma en el proceso penal. Por ello, estamos de acuerdo con el razonamiento del primer fallo de la Corte Suprema cuando señala que la suspensión del juicio es una facultad, "y no una obligación", del tribunal, que sólo podrá decretarse cuando concurran motivos de absoluta necesidad ${ }^{20}$.

\section{2.- ¿Cuál es la posición de la víctima en el nuevo proceso penal? $¿$ Puede tener el estatus de testigo?}

La segunda interrogante surge a partir de la afirmación categórica de la Corte, en su segundo fallo, de que la víctima no tiene la calidad de testigo, porque no es un tercero ajeno al procedimiento sino que es un interviniente o sujeto procesal, calidades que parecieran ser incompatibles en el criterio del alto Tribunal.

No cabe duda que un importante objetivo del nuevo sistema de enjuiciamiento criminal fue conferir una mayor participación a la víctima en el proceso penal, sin necesidad de conferirle patrocinio y poder a un abogado y constituirse en parte querellante, restituyéndole protagonismo en la solución del conflicto que le afecta principalmente. Para ello, la considera interviniente en el procedimiento (art. $12 \mathrm{CPP}$ ) y le reconoce diversos derechos en cuanto tal (art. 109 CPP).

Las afirmaciones de la sentencia carecen, sin embargo, de fundamento. En efecto, por un lado, ella declara incompatible el estatus de interviniente del procedimiento con el de testigo, lo que no resulta debidamente justificado, y, por otro, incluye un

\footnotetext{
17 Derecho procesal penal..., cit., p. 544-5.

18 Derecho procesal penal...cit., p. 545.

${ }^{19}$ HORVITZ/LOPEZ, cit., pp. 96 y ss.

20 Considerando noveno, s. 30.09.2002.
} 
elemento en la definición de testigo que no se expresa ni se infiere de ninguna de las disposiciones del Código, cual es que se trate de un tercero ajeno al procedimiento.

Respecto de la primera cuestión, la circunstancia que la víctima u ofendido sea considerado interviniente en el procedimiento, como forma de relevar su participación en la solución del conflicto jurídico-penal que subyace al delito, no impide que pueda asumir eventualmente la calidad de testigo en el procedimiento ${ }^{21}$. En efecto, la ley otorga a la víctima ciertos derechos en el proceso penal al tiempo que le reconoce calidad de interviniente del mismo (artículos 12 y 109 del CPP); pero junto a tales derechos le impone también ciertos deberes como cualquier ciudadano que debe colaborar con la persecución penal de los delitos, entre ellos, el de comparecer al tribunal y prestar declaración testimonial. La ley no hace excepción a esta carga procesal en tanto ofendido por el delito ${ }^{22}$, sino en mérito - como ya vimos- a consideraciones de orden personal, de secreto o a la investidura del afectado. Por ello, yerra la sentencia al argumentar sobre la hipótesis de "una especie de obligación de hacerse oir a toda costa cuando el Ministerio Público o el Tribunal lo juzgue oportuno para el éxito de la investigación o para el esclarecimiento de los hechos" 23 , haciendo con ello referencia al derecho a ser oída con relación a diversas actuaciones del procedimiento ${ }^{24}$, pues confunde el plano de los derechos con el de los deberes de la víctima en el proceso penal.

Con relación a la segunda cuestión planteada, el artículo 298 del Código Procesal Penal, que inaugura el párrafo sobre los testigos, es claro y preciso al establecer "que toda persona que no se encuentre legalmente exceptuada deberá concurrir al llamamiento judicial practicado con el fin de prestar declaración testimonial (...)"25. El ofendido, al igual que cualquier persona que tenga conocimiento directo o indirecto de los hechos objeto de la persecución penal, tiene la obligación de comparecer y declarar sobre los mismos salvo que en él concurran alguna de las hipótesis legales de excepción al deber de comparecencia (artículo $300 \mathrm{CPP}$ ) o de declarar, ya sea por motivos personales (artículo 302 CPP) o de secreto (artículo 303 CPP).

\footnotetext{
${ }^{21}$ Del mismo parecer, aunque con matices, CHAHUAN pues, aunque este autor señala que "la víctima no puede ser identificada - en sentido técnico-riguroso- con un testigo", no se observa, en su trabajo, ninguna consecuencia práctica relevante para su distinción. En efecto, declara que "ello no impide que pueda declarar en los mismos términos que un testigo y, por ende, para efectos prácticos y de consecuencias procesales los conceptos se identifican (...)". Afirma que es posible compeler a la víctima a declarar, de conformidad con lo dispuesto en el artículo 33 CPP (CHAHUAN (S) "Notas sobre la declaración de imputado y víctimas en el nuevo proceso penal" en Semana Jurídica No 110, 16 al 22 de Diciembre de 2002, pp. 5-6.)

${ }^{22}$ Hay casos en que la ley sí ha exceptuado expresamente a la víctima de ciertos deberes procesales. Así, el artículo $3^{\circ}$ de la Ley 19.617 (D.O. 12 de Julio de 1999), que modificó diversos cuerpos legales en materias relativas al delito de violación y otros abusos sexuales, añadió un inciso final al artículo 351 del Código de Procedimiento penal, que establece, en relación al careo, lo siguiente: “Tampoco procederá el careo entre inculpados o procesados y la víctima en los delitos contemplados en los artículos 361 a 367 bis del Código Penal y en el artículo 375 del mismo cuerpo legal. Si el juez lo estima indispensable para la comprobación del hecho o la identificación del delincuente, deberá emplear el procedimiento indicado en el inciso primero del artículo 355, reputándose a la víctima como testigo ausente, a menos que ella consienta expresamente en el careo". Esta excepción al derecho del imputado a interrogar y contrainterrogar personalmente a los testigos de cargo es una tendencia generalizada en el derecho comparado, y ha sido fuertemente criticada por la doctrina más garantista (En general, sobre las leyes de protección a la víctima en Alemania, vid. HIRSCH, cit., pp. 98 y ss. HASSEMER (W) Crítica al derecho penal de hoy, Ad-Hoc, Buenos Aires, 1995, pp. 94 y ss.)

${ }^{23}$ Considerando $3^{\circ}$, s. 2.10 .02 .

24 Artículo 109, letras d) y e) CPP.

${ }^{25} \mathrm{El}$ subrayado es nuestro.
} 
Horvitz - Estatus de la víctima en el proceso penal

En el derecho comparado y, especialmente, en el de los países que sirvieron de modelo al nuevo CPP, no cabe duda que una de las formas de participación tradicional de la víctima en el proceso penal ha sido la de informante del hecho a la policía y de testigo del procedimiento. Esta función clásica la ha desempeñado incluso en aquellos sistemas que no admiten la figura del querellante particular dentro del proceso penal26.

En el sistema procesal penal chileno antiguo, por otro lado, existen normas que se refieren expresamente a la calidad de testigo que puede tener el ofendido. Así, el artículo 206 del Código de Procedimiento Penal, ubicado en el párrafo sobre los testigos y referido al orden de los testimonios, expresa que "se comenzará el examen por aquellos a quienes se presuma sabedores del hecho, entre los que deben contarse el ofendido, las personas de su familia y aquellas que dieron parte del delito".

Que el Código Procesal Penal haya conferido al ofendido el estatus procesal de interviniente o sujeto procesal, sin necesidad de constituirse en querellante, no significa elevarlo a una categoría que lo excluya de las cargas del proceso. Así, la víctima constituida en querellante en el antiguo proceso penal era inequívocamente parte del mismo, y sin embargo, nunca se pretendió excluirlo de la carga de prestar declaración testimonial si ella resultaba indispensable. Además, se plantea una última pregunta en relación a este tema. La víctima que voluntariamente desea comparecer a declarar al juicio oral, ¿en qué calidad será ofrecida su declaración por la parte que la presenta? El fallo de la Corte Suprema no admite que pueda declarar en calidad de testigo; sin embargo, no existe ninguna otra alternativa posible o prevista por el Código. No existe una regulación especial para la declaración de las "víctimas" en el juicio ${ }^{27}$ y no parece razonable afirmar que la víctima "adquiere" el estatus de testigo cuando acepta declarar voluntariamente. Por otra parte, tampoco puede equipararse la posición del ofendido con la del imputado, como pareciera desprenderse del considerando tercero del fallo, por las razones que examinaremos en el siguiente apartado.

\section{3. ¿'Tiene la víctima el mismo estatus que el imputado o son ellos equiparables?}

La víctima no tiene el mismo estatus que el imputado en el proceso penal chileno, aunque ha habido intentos en el derecho comparado por igualarlos. Así, en Alemania, se ha buscado construir una "igualdad de armas o de posiciones procesal" limitada entre imputado y víctima ${ }^{28}$. SCHÜNEMANN ha criticado que esta tendencia podría conducir fácilmente a que los derechos del ofendido sean ampliados a costa de las garantías procesales del imputado; para este autor no puede existir igualdad de posiciones entre imputado y ofendido en la relación procesal penal pues la controversia exclusivamente penal que en él se ventila se refiere al problema de la existencia de la

\footnotetext{
${ }^{26}$ Un panorama general de derecho comparado se puede ver en: ESER (A) "Acerca del renacimiento de la víctima en el procedimiento penal", en AA.VV De los delitos y de las víctimas, Ad-Hoc, Buenos Aires, 1992, pp. 13 y ss.; sobre la situación alemana, vid. HIRSCH (H.J) "Acerca de la posición de la víctima en el derecho penal y en el derecho procesal penal” en AAVV De los delitos..., cit., pp. 91 y ss., esp. 101.

27 Cuando se trata de medios de prueba que recaen en personas, el Código distingue constantemente entre "testigos, peritos e imputados"; "acusados y testigos", "peritos y testigos"; Cfr. artículos 329, 331, 332 CPP.

28 Así, las sucesivas Leyes de protección a las víctimas"; vid. RIESS , "Der Strafprozess und der Verletzte eine Zwischenbilanz", Jura, 1987, p. 284.
} 
pretensión punitiva del Estado. Desde esta perspectiva, todo está en juego para el acusado; no así para la víctima ${ }^{29}$.

En la misma línea de argumentación, contraponer las expectativas de la víctima y los derechos y garantías del infractor, como otrora lo hiciera el positivismo criminológico $^{30}$, puede conducirnos a negar los derechos del delincuente. En efecto, esta corriente de pensamiento de fines del s. XIX apeló sistemáticamente a los intereses de la víctima del delito, pero con un propósito antigarantista, como coartada defensista ${ }^{31}$.

Por las razones señaladas precedentemente, no estamos de acuerdo con la Corte cuando afirma que: "Resultaría ciertamente paradójico que, mientras se reconoce siempre a los imputados el derecho a callar o a decir sólo aquello que considere conveniente, como se deduce del contexto del Código Procesal penal y, en especial, de sus artículos 98, 194, 195 y 326, el ofendido, en cambio, se viese forzado a prestar declaración, incluso contra su voluntad"32. La comparación es inadmisible. El derecho a guardar silencio del imputado deriva de la presunción de inocencia que asiste a todo ciudadano a quien se dirige una imputación jurídico-penal mientras no se establezca su culpabilidad en una sentencia judicial, garantía recogida explícitamente en los tratados internacionales sobre derechos humanos ratificados por Chile y actualmente vigentes. De allí que el imputado no tenga obligación de colaboración con el Estado al esclarecimiento del delito que se le atribuye y que sus declaraciones en el proceso sean facultativas y deban ser vistas como medios de defensa. La víctima sí tiene un deber de colaboración y no puede, por tanto, "declinar su interés en los resultados" del proceso y, por consiguiente, "su derecho a expresar su verdad sobre los hechos"33.

\section{II.4. ¿Puede la víctima ser compelida a declarar en el juicio?}

En consecuencia, si la víctima no comparece al juicio para declarar como testigo, habiendo sido debidamente notificada al efecto, puede ser compelida a realizar tales actuaciones en la forma prevista en el artículo 299 CPP. Y no sólo puede ser compelido a declarar. En la redacción previa a la Ley 19.789, de 30 de Enero de 2002, el inciso $2^{\circ}$ del artículo 197 establecía expresamente que si "fuere menester examinar al ofendido, el fiscal le solicitará que preste su consentimiento. De negarse, solicitará la correspondiente autorización al juez de garantía, exponiéndole las razones en que se hubiere fundado la negativa", disposición que evidentemente supone la posibilidad de forzar a la víctima a practicarse el respectivo examen en caso de concederse la autorización judicial. La Ley 19.789 no derogó esta hipótesis sino que uniformó la situación del ofendido con la del imputado, respecto del cual, en la antigua regulación, se requería siempre autorización

\footnotetext{
${ }^{29}$ SCHUNEMANN (B) "Zur Stellung des Opfers im System der Strafrechtpflege" en NStZ, 1986, p. 193 y 439.

30 ENRICO FERRI escribía, en 1887, que: "Se ha exagerado demasiado a favor de los delincuentes...(y la conciencia universal reclama) se ponga fin a exagerados sentimentalismos a favor de los malhechores, cuando se olvidan la miseria y los dolores de tantos millones de pobres honrados..." (Los nuevos horizontes del derecho y del procedimiento penal (trad. de Pérez Oliva), Madrid, Góngora, 1887, IX.

31 Vid. sobre el particular, GARCIA-PABLOS (A) "Sobre la función de la víctima en el estado de derecho: víctima, polícitica criminal, criminología y política social", en Derecho Penal y Crimininología. Revista del Instituto de Ciencias Penales y Criminológicas de la U. Externado de Colombia, vol. XIV No 46, Enero/Abril, 1992, pp. 35 y ss.

32 Considerando $3^{\circ}$ s. 2.10.02.

${ }_{33}$ Considerando $3^{\circ}$ de la sentencia 02.10 .02 .
} 
Horvitz - Estatus de la víctima en el proceso penal

judicial ${ }^{34}$. En consecuencia, no cabe duda que la víctima puede ser obligada a colaborar en las actuaciones de investigación del delito que la afectó.

Evidentemente, y en cuanto el ministerio público tiene el deber de asistir a la víctima en todas las fases del procedimiento y conferirle la debida protección, debe evitar llegar a la situación de solicitar medidas compulsivas o apremios en su contra cuando no comparezca a declarar al juicio. En tal sentido, comparto la opinión del máximo tribunal en el sentido de evitar la victimización secundaria del ofendido procurando buscar soluciones adecuadas al caso particular de que se trate ${ }^{35}$, especialmente si la situación de desprotección de la víctima proviene de desatención o falta de asistencia adecuada y oportuna del Ministerio Público ${ }^{36}$. En general, la doctrina comparada coincide en una constatación empírica bastante propagada: la víctima se siente maltratada por el sistema legal. Como señala GARCIA-PABLOS, "sabe de la importancia de su colaboración con la policía y la justicia y, sin embargo, comprueba cómo no recibe un trato equitativo que compense los perjuicios y molestias de todo tipo que dicha cooperación le ocasiona. Los profesionales del sistema ignoran sus actitudes y necesidades, le niegan el rol que efectivamente ostenta. Es imprescindible, pues, redefinir el rol de la víctima-testigo, y concienciar a todos quienes intervienen en el proceso penal de sus actitudes y expectativas. Ponderar los perjuicios económicos, familiares, laborales y de la más variada índole que experimenta la víctima cuando presta su colaboración a la justicia. Atenderla e informarla puntualmente de las vicisitudes del proceso, del significado, a menudo enigmático para ella, de los ritos y ceremonias procesales. De este modo, no sólo se haría justicia con la víctima: se fomentaría su colaboración con el sistema legal y se mejoraría cualitativamente el funcionamiento de éste"37.

En consecuencia, la utilización de apremios debe ser el último recurso que se ocupe para procurarse la colaboración de la víctima en el juicio; en el considerando $5^{\circ}$ del fallo se señala, en este sentido, que la Fiscalía "debe agotar los medios que la ley le franquea para obtener esa cooperación en forma voluntaria (...)". Una víctima asustada o renuente a declarar que es compelida coactivamente a hacerlo no será, con mucha probabilidad, una gran colaboradora del órgano de persecución penal pública.

Finalmente, la eficacia de la acusación no sólo dependerá -o al menos no debería en todos los casos- de la declaración de la víctima. Baste pensar en todos aquellos delitos en que no existe una víctima o ella es de carácter colectivo, como en el delito de tráfico ilícito de estupefacientes. El ministerio público deberá evaluar, en aquellos casos en que no cuente con la colaboración del ofendido, la posibilidad de prescindir de su declaración y/o explorar la existencia de otros medios de prueba igualmente eficientes para sustentar su acusación en el juicio.

\footnotetext{
${ }^{34}$ En el mismo sentido, CHAHUAN, cit., p. 6.

35 Sobre la victimización secundaria, vid. BUSTOS (J)/LARRAURI (E): Victimología: presente y futuro (Hacia un sistema penal de alternativas), PPU, Barcelona, 1993, pp. 43 y ss.

${ }^{36}$ No hay que olvidar que el Ministerio Público dispone de Unidades de Atención a las Víctimas y Testigos, uno de cuyos principales objetivos es dar protección y asistencia a las víctimas en todas las etapas del procedimiento. Vid. Instrucción $\mathrm{N}^{\circ} 11$, sobre atención y protección a las víctimas en el nuevo Código Procesal Penal en Ministerio Público/Fiscalía Nacional, Reforma Procesal Penal (Instrucciones Generales Nos 1 a 25 Septiembre-Noviembre 2000), Editorial Jurídica, 2001, pp. 147 y ss.

37 "Sobre la función de la víctima...", cit., pp. 78-79.
} 
REJ - Revista de Estudios de la Justicia - No 3 - Año 2003

Lo que, en nuestra opinión, no resulta en modo alguno de recibo es el considerando contenido en la letra g) del voto disidente del fallo que comentamos. Allí se afirma que: “(...) de no aceptarse la tesis que se sustenta en el recurso el éxito de la reforma procesal penal puede verse seriamente afectado pues bastaría que los imputados o sus familiares amenazaran al ofendido o a sus parientes y éste no comparezca, y el Tribunal debería absolver a los imputados por falta de pruebas, lo que resultaría pernicioso en las regiones donde existe una población numerosa y una gran cantidad de delitos de robo con intimidación y/o violencia, como el de autos".

En primer lugar, el artículo 331 letra c) del Código autoriza para introducir mediante lectura al juicio los registros en que constaren declaraciones anteriores de testigos (evíctima?), peritos o imputados, cuando la no comparecencia de los mismos "fuere imputable al acusado". En consecuencia, sólo se requiere probar que existió alguna forma de coacción en contra del acusado.

En segundo lugar, la sola incomparecencia del ofendido al juicio no debería necesariamente llevar a la absolución del acusado si existen otros medios de prueba que produzcan convicción en el tribunal más allá de toda duda razonable. Contrario sensu, la sola declaración del ofendido no bastará, regularmente, para adquirir convicción sobre la culpabilidad del acusado.

Y, por último, no nos parece adecuado vincular el éxito o fracaso de la reforma procesal penal en las necesidades de seguridad ciudadana de la población, pues la finalidad del proceso penal no es la obtención de sentencias condenatorias para satisfacer tales demandas de seguridad, sino el juzgamiento de personas imputadas de delitos con pleno respeto de los derechos y garantías que les acuerda el Estado de Derecho. 